\title{
Estratégias retóricas na controvérsia moral sobre a legalização do aborto: o caso da anencefalia no Brasil *
}

Flávia Regina Guedes Ribeiro ${ }^{1}$

Mary Jane Paris Spink²

RIBEIRO, F.R.G.; SPINK, M.J. Rhetorical strategies in the moral controversy over legalization of abortion: the case of anencephaly in Brazil. Interface - Comunic., Saude, Educ., v.16, n.40, p.35-49, jan./mar. 2012.

The way in which rhetorical strategies are constructed in the controversy over abortion in Brazil is discussed. The analysis focuses on two documents: the Minister Marco Aurélio's injunction in 2004, which authorized termination of anencephalic pregnancy, and the Federal Attorney General's opinion, which was against this decision. The methodology consisted of interpreting the strategic resources of the arguments for and against legalization of abortion. The arguments in favor were sustained in the rhetoric of valuing the lives of pregnant women who would have more interests to be protected than such fetuses would, since the women's lives are biographically invested, while investment in the lives of such fetuses would only be of biological nature. The arguments against have constructed rhetoric defending the fetus's life because it belongs to the human species. The analysis indicates that the overlapping of religious values in evaluating reproductive rights encumbers the implementation of women's healthcare.

Keywords: Rhetoric. Anencephaly. Abortion. Women's healthcare.
Discute-se como as estratégias retóricas são construídas na controvérsia sobre o aborto no Brasil. A análise focaliza dois documentos: a liminar do Ministro Marco Aurélio que, em 2004, autorizou a interrupção da gestação de anencefálicos, e o parecer do Procurador-Geral da República, que se manifestou contrário a essa decisão. A metodologia consistiu na interpretação dos recursos estratégicos da argumentação favorável e da contrária à legalização do aborto. Os argumentos favoráveis sustentaram-se na retórica de valorização da vida da gestante, que teria mais interesses a serem protegidos do que o feto, por ser esta investida biograficamente, enquanto o investimento na vida do feto seria apenas de caráter biológico. Os argumentos contrários construíram uma retórica de defesa da vida do feto por este pertencer à espécie humana. A análise indica que a sobreposição de valores religiosos na avaliação dos direitos reprodutivos atravanca a efetivação da assistência à saúde da mulher.

Palavras-chave: Retórica. Anencefalia. Aborto. Saúde da mulher.
* Elaborado com base em Ribeiro (2008); pesquisa financiada pelo CNPq.

Departamento de Psicologia, Universidade Federal de Alagoas, Campus Arapiraca,

Unidade de Ensino Palmeira dos Índios. Rua Sonho Verde, s/n, Eucalipto. Palmeira dos Índios, AL, Brasil. 57.606-100. frgribeiro@palmeira. ufal.br.

2 Programa de Estudos Pós-Graduados em Psicologia Social, Pontifícia Universidade Católica de São Paulo. 


\section{Introdução}

Estima-se que 68 mil mulheres morrem, por ano, em todo o mundo, em decorrência do aborto inseguro. Esses números levam à estimativa de uma razão de mortalidade de 367 mortes por cem mil abortos inseguros, o que é superior à taxa de mortalidade causada pelo aborto seguro (Organização Mundial da Saúde, 2003). A razão de morte por aborto seguro é até menor do que a razão de morte materna. Ou seja, interromper uma gravidez utilizando métodos adequados é mais seguro do que levar uma gravidez adiante, mesmo que normal e sem complicações. Não há dúvidas, portanto, de que o aborto inseguro é um problema de saúde pública.

O aborto inseguro é a quinta causa de morte materna no Brasil. Aproximadamente 29,7 milhões de reais são gastos, anualmente, com internações decorrentes de aborto. Importa ressaltar que se configuram no debate atual sobre a legalização do aborto: (a) as conquistas do movimento feminista, consubstanciadas em documentos nacionais e internacionais, no sentido de a mulher ser considerada como capaz de tomar decisões éticas sobre sua sexualidade e reprodução; e (b) os avanços da medicina e da genética relacionados ao processo de fecundação, desenvolvimento do feto e embrião e à segurança dos métodos para interromper uma gravidez (Rede Feminista de Saúde, 2005).

O debate sobre o aborto, não raramente, costuma provocar reações díspares, mobilizando a população de forma emocional, impondo ocupação de posições antagônicas, nem sempre portadoras de argumentos claros que sustentem, convincentemente, a adesão, seja a um ou outro posicionamento (Domingues, 2008).

O caráter legal ou ilegal do aborto induzido constitui um tema complexo no âmbito dos conflitos morais. Diferentes posições políticas, morais e religiosas enfrentam-se cotidianamente no tratamento do tema. A busca de consenso ou, mesmo, de diálogo entre os extremos morais envolvidos no debate sobre a moralidade do aborto acarreta uma disputa acirrada, em meio a embates, enfrentamentos e articulações políticas.

Este artigo trata das estratégias retóricas usadas na controvérsia moral acerca do aborto induzido nos casos de anencefalia. Buscamos investigar como os discursos são organizados retoricamente pelos diferentes atores sociais envolvidos na contestação de sentenças argumentativas acerca do tema.

Focalizaremos nossa análise no esforço de entender como sentenças morais são usadas argumentativamente para defender posições adversas sobre o aborto. Para tanto, elegemos o caso da anencefalia como objeto de investigação. Nossos objetivos foram: identificar e descrever os argumentos usados na controvérsia moral sobre o aborto que ponham em evidência as crenças morais favoráveis e contrárias a sua prática; analisar esses argumentos buscando entender a defesa sobre qual vida merece ser vivida; e investigar as estratégias retóricas usadas para organizar os argumentos dos atores em debate.

O caso da anencefalia é prototípico por colocar à prova os limites da argumentação polarizada com a qual vem sendo tratado o tema do aborto; de um lado, a ideia feminista de que o corpo pertence às mulheres, e, de outro, o direito potencial à vida do feto, segundo princípios morais da hierarquia da Igreja Católica.

A concessão, em $1^{\circ}$ de julho de 2004, da liminar do Ministro Marco Aurélio Mello que autorizou, temporariamente, a interrupção da gestação de fetos anencefálicos, impulsionou os atores sociais envolvidos no debate a se posicionarem sobre a moralidade do aborto, fazendo com que os argumentos de defesa e objeção viessem à tona. A estratégia argumentativa desta ação foi a de demonstrar que outros princípios constitucionais devem fazer parte do debate público e político sobre o aborto (Dinis, Vélez, 2008). Considerando esse aspecto, elegemos o caso da anencefalia para ser estudado nesta pesquisa.

Apesar de o tema estar em discussão desde a cassação da liminar em 2004, ele ainda não foi votado em definitivo pelos 11 Ministros do STF. Em setembro de 2008, o relator da Arguição de Descumprimento de Preceito Fundamental (ADPF) 54, Ministro Marco Aurélio Mello, propôs uma audiência pública, onde foram ouvidos representantes de 25 diferentes instituições, ministros de Estado e cientistas, entre outros. A audiência durou quatro dias, durante os quais argumentos, opiniões, 
palestras e dados científicos foram apresentados, tendo, de um lado, defensores do direito das mulheres de decidir sobre prosseguir ou não com a gravidez de fetos anencéfalos, e, do outro, aqueles que acreditam ser a vida intocável, mesmo no caso de má-formação incompatível com a vida extrauterina.

A controvérsia pública sobre o aborto nos casos de anencefalia surgiu quando a Confederação Nacional dos Trabalhadores da Saúde (CNTS), em 16 de junho de 2004, entrou com uma ação no Supremo Tribunal Federal (STF) usando uma ferramenta jurídica chamada Arguição de Descumprimento Fundamental (ADPF-54), que gerou a liminar do Ministro Marco Aurélio Mello autorizando a interrupção da gestação em tais casos. O Procurador-Geral da República, Cláudio Fonteles, que tem como obrigação institucional manifestar-se frente às decisões do Supremo, emitiu um parecer contrário à aprovação da liminar, o que gerou a sua cassação e consequente votação como improcedente pelos Ministros do STF. Nesse embate, os dois documentos - liminar e parecer - compõem o contexto agonístico (Billig, 1991), de enfrentamento de versões sobre a legitimidade moral da legalidade do aborto de fetos anencefálicos.

O objetivo deste artigo é discutir os resultados da análise retórica feita a partir dos argumentos presentificados na liminar do Ministro do STF e do parecer do Procurador-Geral da República. Para tanto, iniciaremos com a apresentação do enquadre conceitual e teórico que sustenta a análise; em seguida, explicitamos os procedimentos de pesquisa, para, então, apontarmos a descrição da interpretação dos documentos de domínio público estudados.

\section{Enquadramento conceitual e teórico}

A retórica é considerada, nesta pesquisa, como um aspecto da relação antagônica entre versões: como se contrapõe uma descrição a outra descrição alternativa e/ou contrária, e como ela se organiza, ao mesmo tempo, para resistir a uma oposição (Billig, 1991). Ou seja, a retórica é o modo como argumentos opostos se enfrentam numa controvérsia. Para a análise retórica da controvérsia sobre a moralidade do aborto de fetos anencefálicos, nos apoiaremos nas categorias analíticas: gêneros retóricos e recursos estratégicos.

\section{Gêneros retóricos}

Os teóricos da retórica identificaram três gêneros persuasivos ou retóricos: o forense, o deliberativo e o epidêitico (Gross, 1990; Fahnestock, 1986 apud Leach, 2002), categorizados a partir do objetivo, do público, da situação e do tempo. A retórica forense é própria dos tribunais, onde a discussão se centra na natureza e na causa de acontecimentos passados, e os interlocutores devem persuadir um terceiro grupo de que sua explicação dos acontecimentos passados é uma explicação "verdadeira". A retórica deliberativa é encontrada na arena política, onde o debate se centra no melhor rumo possível de uma ação futura. Esta forma de persuasão é, portanto, orientada para o futuro e, muitas vezes, especulativa. A retórica epidêitica está centrada em temas contemporâneos e na avaliação se determinado indivíduo ou acontecimento merecem louvor, são culpados ou devem ser censurados. As formas clássicas de retórica epidêitica são orações fúnebres e cerimônias de premiação.

\section{Recursos estratégicos}

Segundo Potter (1996), as pessoas utilizam estratégias argumentativas para produzirem relatos que atendam a seus interesses, sem serem consideradas explicitamente como interessadas. O dilema de manejar sentidos em favor de interesses, sem que se deixem evidentes as estratégias de manipulação, pode ser articulado de diferentes formas por meio dos relatos. Ou seja, as pessoas podem desempenhar ações atributivas, tais como: culpar indiretamente ou implicitamente, se desculpar ou recusar convites, pela produção de um relato factual e ostensivamente desinteressado. Para o estudo desses relatos, Potter propõe a análise de recursos estratégicos. São eles: 
a) Direito categorial: onde a veracidade de um relato particular será garantida pelo direito de membro da categoria do falante, ou seja, espera-se que pessoas em categorias particulares - oficiais ou não - tenham conhecimento de certas coisas ou tenham certos esquemas epistemológicos.

b) Descrição vívida: rica em detalhes contextuais e incidentes. Pode ser usada para criar uma impressão de experiência perceptual, assim como indicar que o falante ou escritor tem um esquema particular de observação.

c) Narrativa: um relato pode ter sua veracidade aumentada por fixá-lo numa sequência narrativa particular na qual o evento é esperado ou mesmo necessário.

d) Imprecisão sistemática: é a retórica contrária da descrição vívida e da narrativa. Fundamentase no fato de que a riqueza de detalhes pode garantir a veracidade do relato, como, também, pode proporcionar elementos para uma contestação.

e) Relatos empiricistas: característica das falas e escritos científicos. Trata o fenômeno como agente e apaga o observador inteiramente ou o trata como um recipiente passivo. Neste discurso, os fatos impõem-se aos atores humanos, que têm um papel inteiramente secundário, no qual o observador recolhe a informação que o meio oferece.

f) Retórica de argumento: constrói afirmações de lógica, silogística ou outro tipo de argumento bem conhecido que fornece um meio de torná-los externos ao falante ou escritor. Esquemas deste tipo são particularmente importantes quando versões estão sendo mobilizadas para proporcionar inferências atributivas particulares, como, por exemplo, de culpa, por apresentá-las como requeridas pelos eventos ou ações em si mesmas, mais do que desejadas pelo falante.

g) Formulações de casos extremos: esta estratégia foi explorada por Pomerantz (1986 apud Potter, 1996), que observou como se pode tornar um relato mais efetivo ao direcioná-lo aos extremos de dimensões relevantes de julgamento.

h) Consensos e confirmação: uma maneira de garantir a factualidade de uma versão é descrevêla de acordo com testemunhas ou como confirmada por observadores independentes. Às vezes, o consenso combina com a normatividade, o que combina aquilo que é próprio da categoria (norma) com aqueles que concordariam com tal categoria (consensos); podendo ser agrupado numa formulação de caso extremo.

i) Listas e contrastes: oratórias políticas atestam para a efetividade retórica dessas estratégias. A lista é combinada com um contraste que formula a versão factual em oposição a uma alternativa ameaçadora, que é formulada de uma maneira problemática ou pouco convincente.

\section{Procedimentos de pesquisa}

Para o objetivo de descrever a controvérsia moral acerca do aborto induzido, foi preciso escolher uma situação social que fosse prototípica do confronto moral sobre a questão e que publicizasse as diferentes posições morais no debate sobre a legalização do aborto. Consideramos que o caso da anencefalia no STF é basilar por clamar, compulsoriamente, que os atores sociais envolvidos com o tema do aborto se posicionem.

Para a consecução da análise discursiva, escolhemos dois documentos jurídicos que podemos considerar como protagonistas do debate: a liminar do Ministro Marco Aurélio e o parecer do Procurador-geral da República. Realizamos uma análise retórica que consistiu na interpretação da utilização dos recursos estratégicos como categorias analíticas do conteúdo argumentativo dos textos jurídicos supracitados.

\section{Descrição e análise dos documentos de domínio público}

Para interpretação das estratégias retóricas, presentificadas nos documentos analisados, buscamos apreender como os conceitos analíticos da retórica organizam e expressam os pressupostos morais dos autores em controvérsia, usados para persuadir a respeito das suas respectivas posições e convicções 
acerca do aborto. Nessa seção, apresentamos a análise discursiva realizada a partir dos documentos protagonistas da controvérsia: a liminar, do Ministro Marco Aurélio Mello, e o parecer, do Procurador-geral da República, Cláudio Fonteles.

\section{Os usos retóricos na liminar do Ministro Marco Aurélio Mello}

Marco Aurélio Mello foi nomeado Ministro do STF pelo presidente Fernando Collor de Mello, em 1990. Sua atuação, desde então, Ihe rendeu a alcunha de "senhor do voto vencido" pela frequência de vezes em que fica isolado nas decisões do tribunal. Suas atitudes quase sempre geram polêmicas e controvérsias, como foi o caso da liminar em que autorizou a aborto de fetos anencefálicos.

A medida liminar é uma providência cautelar destinada a preservar a possibilidade de satisfação pela sentença do direito do requerente. Tratase de uma decisão de caráter urgente, cujo objetivo é evitar perdas para uma das partes antes que o mérito de uma causa seja julgado. Ou seja, é uma ordem judicial destinada à tutela de um direito em razão da provável veracidade dos fundamentos invocados por uma das partes e da possibilidade de ocorrer dano irreparável em decorrência do atraso da decisão. A liminar foi o instrumento jurídico usado pelo Ministro Marco Aurélio Mello para autorizar, provisoriamente, a "antecipação terapêutica do parto" nos casos de gestação de anencéfalos. O Ministro considerou a causa urgente e entendeu que o direito da gestante de interromper a gestação poderia ficar prejudicado até o julgamento em definitivo pelo STF.

No texto da liminar, o Ministro Marco Aurélio Mello repetiu alguns enunciados da petição inicial (ADPF-54) para justificar a sua concordância em autorizar o pedido da ação. No desenvolvimento do conteúdo da liminar, foi apresentado o pedido da Confederação Nacional dos Bispos do Brasil (CNBB)

${ }^{3}$ Amicus Curiae (amigo da corte) é um instituto de matriz democrática que permite que terceiros passem a integrar a demanda jurídica, para discutir objetivamente teses que vão afetar a sociedade como um todo, quando admitidos, nos limites subjetivos da coisa julgada.

${ }^{4}$ Primeiro habeas corpus a ser julgado na Suprema Corte brasileira em favor da gestante de feto anencefálico. de participar do processo como amicus curiae ${ }^{3}$, o que foi vedado pelo relator da ação. Também foi narrada a história e desfecho do habeas corpus 84.025$6 / \mathrm{RJ}^{4}$, com trechos dos pronunciamentos da primeira relatora que autorizou a antecipação do parto, e da segunda, que suspendeu a autorização. A liminar foi concluída com uma eloquente defesa do Ministro Marco Aurélio pelo direito das mulheres de anteciparem terapeuticamente o parto em casos de diagnóstico de anencefalia.

A referida liminar foi composta por 16.021 caracteres e seis páginas. O gênero retórico forense foi nela caracterizado pela oratória repleta de citações normativas - leis e jurisprudências. A argumentação reproduziu a lógica argumentativa da ADPF-54, com a utilização das linguagens sociais da Biomedicina (para situar o campo do conhecimento legitimado para conceituar a anencefalia), da Psicologia (para atestar os prejuízos emocionais advindos da gestação de fetos anencefálicos) e da linguagem biológica (para descrever o contraste entre uma gestação normal e uma gestação de anencéfalo): "o determinismo biológico faz com que a mulher seja a portadora de uma nova vida, sobressaindo o sentimento maternal [...] Este é o quadro de uma gestação normal [...]" (Mello, 2004, p.07).

$\mathrm{Na}$ análise retórica da liminar, identificamos os seguintes recursos estratégicos: direito categorial, descrição vívida, narrativa, relatos empiricistas, retórica de argumento, consensos e confirmações, e listas e contrastes.

$\mathrm{O}$ uso do direito categorial foi empregado para garantir o direito e autoridade do advogado da CNTS: "A peça, subscrita pelo advogado Luís Roberto 
Barroso, credenciado conforme instrumento de mandato - procuração - de folha 26, anexaram-se os documentos de folha 27 a 148" (Mello, 2004, p.03). O emprego desse recurso também foi realizado para atestar a autoridade concedida ao relator da liminar, o que causou a impressão de sentença incontestável em relação ao direito do Ministro de votar, mesmo que solitariamente - sem os votos dos outros Ministros do STF - em favor do atendimento do pedido da ADPF-54: "Nele lancei visto, declarando-me habilitado a votar, ante o pedido de concessão de medida acauteladora, em 21 de junho de 2004, expedida a papeleta ao Plenário em 24 imediato" (Mello, 2004, p.03). A legitimidade da autoria da ação pela CNTS também foi atestada por meio do recurso direito categorial:

Tenho a Confederação Nacional dos Trabalhadores na Saúde - CNTS como parte legítima para a formalização do pedido, já que se enquadra na previsão do inciso I do artigo $2^{\circ}$ da Lei no 9.882, de 3 de novembro de 1999. Incumbe-se defender os membros da categoria profissional que se dedicam à área da saúde e que estariam sujeitos a constrangimentos de toda ordem, inclusive de natureza penal. (Mello, 2004, p.04)

A estratégia de organizar o argumento recorrendo ao direito de pertencer à categoria de Ministro do STF foi usada para estabelecer o lugar de poder de decisão ocupado pelo relator da liminar. A argumentação foi apresentada de modo a tornar inquestionável o direito de autorizar a antecipação terapêutica do parto nos casos de anencefalia do feto:

Daí o acolhimento do pleito formulado para, diante da relevância do pedido e do risco de manter-se com plena eficácia o ambiente de desencontros em pronunciamentos judiciais até aqui norteados, ter-se não só o sobrestamento dos processos e decisões não transitadas em julgamento, como também o reconhecimento do direito constitucional da gestante de submeter-se à operação terapêutica de parto de fetos anencefálicos, a partir de laudo médico atestando a deformidade, a anomalia que atingiu o feto. É como decido na espécie. (Mello, 2004, p.08)

A descrição vívida compôs a retórica da liminar como estratégia para criar a impressão de que o relator do documento possuía um esquema cognitivo próprio para abordar o tema da gestação de anencéfalos. A riqueza de detalhes na descrição visou construir um discurso coisificador, combinado com uma descrição defensiva, que apresentou como fato o drama vivido pela gestante:

O determinismo biológico faz com que a mulher seja a portadora de uma nova vida, sobressaindo o sentimento maternal. São nove meses de acompanhamento minuto a minuto, de avanços predominando o amor. A alteração física, estética, é suplantada pela alegria de ter em seu interior a sublime gestação. As percepções se aguçam, elevando a sensibilidade. Este o quadro de uma gestação normal, que direciona a desfecho feliz, ao nascimento da criança. Pois bem, a natureza, entrementes, reserva surpresas, às vezes desagradáveis [...]. (Mello, 2004, p.07)

A narrativa foi usada para relatar o episódio em que a CNBB pediu para participar do processo movido pela CNTS. A estratégia foi construir a autoridade do relator para vetar o pedido e atestar a factualidade da falta de enquadre legal do requerimento da CNBB:

A Confederação Nacional dos Bispos do Brasil - CNBB - requer a intervenção no processo em referência, como amicus curiae, conforme preconiza o $\S 1^{\circ}$ do artigo $6^{\circ}$ da Lei 9.882/1999, e a juntada de procuração. Pede vista pelo prazo de cinco dias. O pedido não se enquadra no texto legal evocado pela requerente [...]. (Mello, 2004, p.04)

O recurso estratégico da narrativa também foi invocado para relatar o episódio em que uma gestante de anencéfalo teve seu pedido de interrupção da gestação autorizado e, depois, cassado. A 
sequência narrativa e a apresentação das personagens que compuseram a história contada pelo relator foram organizadas de modo a construir a factualidade do drama vivido pelas gestantes de anencéfalos e atestar a necessidade de se viabilizar outra forma de tratamento do tema:

A situação pode ser assim resumida: em Juízo, gestante não logrou autorização para abreviar o parto. A via-crúcis prosseguiu e, então, no Tribunal de Justiça do Estado do Rio de Janeiro, a relatora, desembargadora Giselda Leitão Teixeira, concedeu liminar, viabilizando a interrupção da gestação. Na oportunidade, salientou: A vida é um bem a ser preservado a qualquer custo, mas, quando a vida se torna inviável, não é justo condenar a mãe a meses de sofrimento, de angústia, de desespero. O presidente da Câmara Criminal a que afetou o processo, desembargador José Murta Ribeiro, afastou do cenário jurídico tal pronunciamento. No julgamento de fundo, o Colegiado sufragou o entendimento da relatora, restabelecendo a autorização. Ajuizado hábeas corpus, o Superior Tribunal de Justiça, mediante decisão da ministra Laurita Vaz, concedeu a liminar, suspendendo a autorização. O colegiado a que integrado a relatora confirmou a óptica, assentando [...]. (Mello, 2004, p.05)

Os relatos empiricistas compuseram a estratégia de convencimento acerca da letalidade da anencefalia. Os relatos foram apresentados de forma a empilhar dados estatísticos que construíram o discurso coisificador da anomalia fetal:

No caso da anencefalia, a ciência médica atua com margem de certeza de 100\%. Dados merecedores da maior confiança evidenciam que fetos anencefálicos morrem no período intra-uterino em mais de $50 \%$ dos casos. Quando se chega ao final da gestação, a sobrevida é diminuta, não ultrapassando período que possa ser tido como razoável, sendo nenhuma a chance de afastarem-se, na sobrevida, os efeitos da deficiência. (Mello, 2004, p.07)

A retórica de argumento foi a estratégia utilizada na liminar para expressar um esquema de racionalidade baseado em fatos. A retórica foi organizada de modo a associar fatos - apresentados como "reais" - aos argumentos que defendiam o direito da gestante de decidir pela interrupção da gestação. A valorização da vida da gestante foi construída discursivamente de modo a apresentar uma descrição ofensiva que se contrapôs à crença de que o feto é potencialmente pessoa, tem uma vida que merece ser protegida ou tem direito à vida pelo simples fato de pertencer à espécie humana. $O$ trecho abaixo ilustra esse tipo de estratégia argumentativa:

A permanência de feto anômalo no útero da mãe mostrar-se-ia potencialmente perigosa, podendo gerar danos à saúde e à vida da gestante. Consoante o sustentado, impor à mulher o dever de carregar por nove meses um feto que se sabe, com plenitude de certeza, não sobreviverá, causa à gestante dor, angústia e frustração, resultando em violência às vertentes da dignidade humana - a física, a moral e a psicológica - e em cerceio à liberdade e autonomia da vontade, além de colocar em risco a saúde, tal como proclamada pela Organização Mundial de Saúde - o completo bem-estar físico, mental e social e não apenas a ausência de doença. Já os profissionais da medicina ficam sujeitos às normas do Código Penal - artigos 124, 126, cabeça, e 128, incisos I e II -, notando-se que, principalmente quanto às famílias de baixa renda, atua a rede pública. (Mello, 2004, p.02)

A organização retórica dos argumentos foi apresentada de modo a intimidar o interlocutor adversário ou opositor das sentenças defendidas no documento. A eloquência da retórica forense combinada com a deliberativa impôs um caráter persuasivo que objetivou levar à crença da ineficiência do sistema jurídico no tratamento dos casos de gestação de anencéfalo. A intimidação se deu pela crítica rigorosa e adjetivada, com implicação de julgamento desfavorável a esse sistema jurídico: 
ESTRATÉGIAS RETÓRICAS NA CONTROVÉRSIA MORAL SOBRE A LEGALIZAÇÃO DO ABORTO:...

Tudo recomenda que, em jogo tema da maior relevância, em face da Carta da República e dos princípios evocados na inicial, haja imediato crivo do Supremo Tribunal Federal, evitandose a decisões discrepantes que somente causam perplexidade, no que, a partir de idênticos fatos e normas, veiculam enfoques diversificados. A unidade do Direito, sem mecanismo próprio à uniformização interpretativa, afigura-se simplesmente formal, gerando insegurança, o descrédito do Judiciário e, o que é pior, com angústia e sofrimento ímpares vivenciados por aqueles que esperam a prestação jurisdicional. Atendendo a petição inicial os requisitos que Ihe são inerentes - artigo $3^{\circ}$ da Lei no 9.882/99 -, é de se dar seqüência ao processo. (Mello, 2004, p.07)

O apelo à legitimidade do conhecimento científico também foi um elemento composicional da retórica de argumento. Tal recurso foi disposto de modo a oferecer uma solução para o tratamento do tema considerando a inviabilidade da vida do feto. Ou seja, a consideração da inexistência de vida do feto implica, a rigor, a atenção à vida da gestante. A vida da gestante deveria ser preservada, uma vez que é uma vida materializada, com investimentos sociais, econômicos e culturais, em detrimento da vida do feto, cujo investimento é considerado em seu limite biológico. Os trechos a seguir ilustram esse tipo de estratégia:

Diante de uma deformação irreversível do feto, há de se lançar mão dos avanços médicos tecnológicos, postos à disposição da humanidade não para simples inserção, no dia-a-dia, de sentimentos mórbidos, mas, justamente, para fazê-los cessar. (Mello, 2004, p.07)

Então, manter-se a gestação resulta em impor à mulher, à respectiva família, danos à integridade moral e psicológica, além de riscos físicos reconhecidos no âmbito da medicina.

(Mello, 2004, p.07)

A retórica de argumento, em algumas passagens do texto da liminar, assumiu uma descrição ofensiva, organizada com o objetivo de coisificar o discurso sobre a defesa da nãocaracterização da antecipação terapêutica do parto como similar ao aborto induzido. $O$ relato teve o desígnio de ser apresentado incontestavelmente como factual. $\mathrm{O}$ argumento foi expresso, literalmente, como irrefutável: "Se assim é - e ninguém ousa contestar -, tratase de situação concreta que foge à glosa própria ao aborto - que conflita com a dignidade humana, a legalidade, a liberdade e a autonomia de vontade". (Mello, 2004, p.07-08)

A estratégia usada para garantir a factualidade da descrição sobre a necessidade de se estabelecer um sistema jurídico que trate eficazmente o tema da antecipação terapêutica do parto foi construída por meio de um relato baseado no testemunho que a CNTS fez ao trazer o desfecho do Habeas Corpus 84.025-6:

Sobre a inexistência de outro meio eficaz para viabilizar a antecipação terapêutica do parto, sem incompreensões, evoca a Confederação recente acontecimento retratado no Hábeas Corpus no 84.025-6, declarado prejudicado pelo Plenário, ante o parto e morte de feto anencefálico sete minutos após. (Mello, 2004, p.02)

A argumentação em defesa do direito da gestante de antecipar o parto também foi realizada de acordo com a sustentação retórica da petição inicial:

Conforme ressaltado na inicial, os valores em discussão revestem-se de importância única. (Mello, 2004, p.07)

Como registrado na inicial, a gestante convive diuturnamente com a triste realidade e a lembrança ininterrupta do feto, dentro de si, que nunca poderá se tornar um ser vivo. (Mello, 2004, p.07) 
A retórica forense combinou-se com a deliberativa para atestar a versão factual defendida pelo relator da liminar. Ele enumerou os direitos da gestante a serem defendidos em oposição, implícita, ao suposto direito do feto à vida: "A um só tempo, cuida-se do direito à saúde, do direito à liberdade em seu sentido maior, do direito à preservação da autonomia da vontade, da legalidade e, acima de tudo, da dignidade da pessoa humana". (Mello, 2004, p.07)

\section{Os usos retóricos no parecer do Procurador-geral}

A publicação da liminar do Ministro Marco Aurélio Mello levou à elaboração do parecer do procurador-geral da República, Cláudio Fonteles, contrário à decisão que autorizou a antecipação terapêutica do parto em casos de anencefalia do feto.

Atualmente, no Brasil, o Procurador-geral da República exerce a chefia do Ministério Público da União e do Ministério Público Federal, além de atuar como procurador-geral eleitoral. É nomeado pelo presidente da República e seu nome deve ser aprovado pela maioria absoluta do Senado Federal. Segundo prevê a Constituição Federal, o procurador-geral da República deve sempre ser ouvido nas ações de inconstitucionalidade e em todos os processos de competência do Supremo Tribunal Federal. Ele também pode promover Ação Direta de Inconstitucionalidade e ações penais para denunciar autoridades, como deputados federais, senadores, ministros de Estado, o presidente e o vice-presidente da República. Além disso, pode propor, perante o STJ: ação penal, representação para intervenção nos Estados e no Distrito Federal e de federalização de casos de crimes contra os direitos humanos.

O procurador-geral da República, na época da publicação da liminar, era Cláudio Fonteles. Fonteles é católico, membro leigo da Ordem de São Francisco, informação que consta na sua biografia publicada no site do Ministério Público 5 . Ingressou no Ministério Público Federal em 1973, e exerceu o cargo de procurador-geral da República de 2003 a 2005. Como parte das suas atribuições, como procurador, Fonteles emitiu parecer acerca da autorização da antecipação terapêutica do parto de fetos anencefálicos, em 2004.

O parecer do procurador-geral da Republica é um documento de natureza jurídica. Nesse parecer, Claudio Fonteles expôs sua opinião especializada sobre o tema da antecipação terapêutica do parto de fetos anencefálicos, indeferindo a autorização manifestada pela liminar. O documento conta com 23.677 caracteres e dez páginas, composto por elementos gramaticais e termos conceituais característicos da linguagem dos tribunais. A retórica forense foi marcada, ao longo de todo o conteúdo, por expressões como "inconstitucionalidade" e "competência do legislador". O empilhamento de argumentos jurídicos, menções a leis e a juristas foi uma constante na argumentação. O procurador limitou-se aos usos sociais da linguagem jurídica, que compôs o gênero retórico forense, situando sua retórica nos limites interpretativos colocados pela compreensão literal das leis que ele referiu. A intertextualidade do documento foi composta, precisamente, pelas citações de trechos dessas leis e dos argumentos dos juristas que ele usou como argumento de autoridade. $\mathrm{O}$ endereçamento do parecer foi feito ao plenário do STF, ao final do documento: "Quer por ser injurídico, no caso apresentado, o recurso à interpretação conforme a Constituição quer pela primazia jurídica do direito à vida, como aqui desenvolvida, o pleito é de ser indeferido". (Fonteles, 2004, p. 10). 
ESTRATÉGIAS RETÓRICAS NA CONTROVÉRSIA MORAL SOBRE A LEGALIZAÇÃO DO ABORTO:...

No parecer de sua autoria, Cláudio Fonteles expressou seu modo de interpretar a legislação penal acerca do aborto induzido. Para ele, somente o que está no texto da lei poderia ser considerado como verdadeiro. Os fatos mencionados pela petição inicial e pela liminar foram desconsiderados pelo procurador, pois, para ele, o que dá sentido aos fatos é a lei; se a lei não estabelece, não é fato. Essa interpretação considerou censurável a interrupção de uma gestação de um feto anencefálico. Cláudio Fonteles se baseou na interpretação literal do texto do art. 128 do Código Penal, que não exclui a aplicação da pena às hipóteses de aborto terapêutico, mas apenas ao humanitário e ao necessário. Esse tipo de interpretação pode ser ilustrado no trecho abaixo:

[...] Bastam-se no que enunciam, e como estritamente enunciam. Aliás, injurídico, data venia, manusear-se com a interpretação conforme a dizer-se que na definição dos tipos penais incriminadores, não seja criminalizada tal situação [...]. As situações extintivas da antijuridicidade, que enuncia, apresentam o sentido inequívoco que a lei enquanto tal apresenta, para que sejam rememoradas as palavras de Rui Medeiros (item 9, deste parecer), sentido inequívoco e preciso, que se completa, e legaliza o aborto: a) para que a mãe não morra (aborto terapêutico); b) se a mãe, vítima de estupro, consente no aborto (aborto sentimental). A situação de anencefalia não se coaduna, por óbvio, nessas situações. $O$ feto anencéfalo não causa a morte da mãe. Afasta-o a própria petição inicial. Se causasse tal situação, ter-se-ia diante o aborto terapêutico. Quanto ao aborto sentimental não há discrepância na abalizada doutrina penal de que sua compreensão é limitadíssima à hipótese que enuncia: gravidez resultante de estupro. (Fonteles, 2004, p. 06)

Os recursos estratégicos - direito categorial, imprecisão sistemática, retórica de argumento e listas e contrastes - foram identificados na análise retórica do parecer do procurador-geral da República, e são descritos a seguir.

O uso do recurso estratégico direito categorial foi marcado pela linguagem autoritária e intransigente do Procurador-Geral. Fonteles fez uso do seu direito de emitir opinião sobre o tema da liminar por exercer a função de Procurador-Geral da República, tentando estabelecer a factualidade de suas descrições recorrendo ao seu lugar de poder, instituído pelo cargo que ocupa. Ele combinou essa estratégia com o recurso consenso e confirmações e ao argumento de autoridade dos textos legais, como, por exemplo, da Constituição Federal: "Estabeleço que o recurso à interpretação conforme à Constituição, pedra de toque do pleito em exame, conduz-nos à reflexão sobre os limites do uso deste instrumento na avaliação dos preceitos normativos". (Fonteles, 2004, p. 02)

O direito categorial também foi usado com a finalidade de comunicar a conclusão dos argumentos do Procurador-Geral, emitindo sua decisão: "Quer por ser injurídico, no caso apresentado, o recurso à interpretação conforme a Constituição, quer pela primazia jurídica do direito à vida, como aqui desenvolvida, o pleito é de ser indeferido". (Fonteles, 2004, p. 10)

A imprecisão sistemática foi o recurso usado por Fonteles para construir uma descrição defensiva sobre o argumento do sofrimento da gestante, defendido pela ADPF-54 e pela liminar. O Procurador utilizou um relato vago e impreciso sobre gestantes, que, ao contrário das afirmações da ADPF-54 e da liminar, sofreriam resignadamente a dor de gestar um feto inviável. A organização retórica visou fornecer formulações globais essenciais para estabelecer o apelo emocional ao sentimento materno, o que seria suficiente para persuadir os interlocutores a respeito da inexistência do risco de vida da gestante e do direito à vida do feto:

De pronto, não são todas as gestantes que, por sua dor, almejam livrar-se do ser humano, que existe em seus ventres maternos. 
Há, outras também, gestantes, que, se experimentam a dor, superam-na e, acolhendo a vida presente em seu ser, deixam-na viver, pelo tempo possível. (Fonteles, 2004, p. 09)

O recurso estratégico imprecisão sistemática assumiu seu caráter persuasivo quando Fonteles afirmou que não seriam todas as gestantes que sofrem ou sentem dor. A estratégia foi construir uma refutação, com base em inferências, dos argumentos defendidos pela CNTS e pelo Ministro Marco Aurélio Mello. As inferências descritas por Fonteles foram fundamentadas na defesa da premissa do direito à vida do feto desde a concepção, implicando a crença de que a vida humana deve ser protegida por ser dotada de valores derivativos (Dworkin, 2003). Ou seja, sua objeção ao aborto se funda no pressuposto de que os fetos são criaturas com interesses próprios, aí incluído o interesse de permanecer vivo. Nos termos de tal afirmação, o aborto é errado por violar o direito de alguém a não ser morto, assim como matar um adulto é normalmente errado por violar seu direito a que não o matem. Na argumentação de Fonteles, esta crença é presentificada nos seguintes termos:

Digo isso para assentar que a dor da gestante não é comum a todas as gestantes, de sorte que, e atento ao princípio jurídico da proporcionalidade, a temporalidade do direito à vida, como desenvolvi nos itens 42/45, retro, sobrepuja, por essa perspectiva, o direito da gestante não sentir a dor, posto que a dor não será partilhada por todas as gestantes, ao passo que todos os fetos anencefálos terão suprimidas suas vidas. (Fonteles, 2004, p. 09)

O discurso ironizador foi componente da construção retórica que inferiu supostos casos ou eventos para justificar a defesa da vida do feto anencefálico. Fonteles afirmou que a interrupção da gestação de fetos anencefálicos impede a doação de órgãos desses fetos, mas não conseguiu sustentar sua defesa, pois ele não mencionou registros ou provas de que esse tipo de doação seria possível.

Ora, o pleito da autora, titulado por órgão que representa profissionais da área da saúde, impede possa acontecer a doação de órgãos do bebê anencéfalo a tantos outros bebês que, se têm normal formação do cérebro, todavia têm grave deficiência nos olhos, nos pulmões, nos rins, no coração, órgãos estes plenamente saudáveis no bebê anencéfalo, cuja morte prematura frustrará a vida de outros bebês, assim também condenados a morrer, ou a não ver. (Fonteles, 2004, p. 10)

A retórica de argumento apresentada no parecer foi organizada a partir de uma lógica de inquérito, do tipo pergunta e resposta, onde o Procurador-geral elaborou questões que ele mesmo respondeu. Essa estratégia imprimiu um caráter de obviedade às sentenças por ele defendidas, estabelecendo uma racionalidade organizada de forma a parecer que nada tem de subjetiva; que seria neutra e externa às descrições feitas por Fonteles, que apenas as comunicou. Os trechos a seguir ilustram esse tipo de uso retórico:

Tudo assim posto, os textos normativos, apresentados pela autora, ensejam a interpretação conforme?

Por certo que não!

E aqui o ponto nodal da controvérsia: a compreensão jurídica do direito à vida legitima a morte, dado o curto espaço de tempo da existência humana?

Por certo que não!

E se assim o é, e o é efetivamente, dada a clareza dos textos normativos importa prosseguir, e indagar, então: a dor temporal da gestante é causa bastante a obscurecer, e então relativizar, a compreensão jurídica do direito à vida, como venho de assentar? Estou em que não.

A retórica de argumento também foi usada para construir um discurso ironizador dedicado a derrubar as versões sobre o risco de vida da gestante, defendidas pela CNTS e pelo Ministro Marco 
ESTRATÉGIAS RETÓRICAS NA CONTROVÉRSIA MORAL SOBRE A LEGALIZAÇÃO DO ABORTO:...

Aurélio Mello: "O feto anencéfalo não causa a morte da mãe. Afasta-o a própria petição inicial. Se causasse tal situação, ter-se-ia diante o aborto terapêutico" (Fonteles, 2004, p. 07).

Fonteles usou a estratégica retórica para construir afirmações acerca da defesa da vida do feto como uma primazia jurídica:

Passo a outra linha de argumentação, e sustento que a vingar a tese do autor, sacrificado está o direito à vida.

Portanto o direito à vida é posto como marco primeiro, no espaço dos direitos fundamentais.

(Fonteles, 2004, p. 07)

Derrubar as afirmações retóricas dos seus dissidentes, a CNTS e o Ministro Marco Aurélio Mello, foi uma estratégia argumentativa do Procurador-Geral, organizada por meio da construção de um discurso ofensivo que visou desconstruir a veracidade das afirmações construídas na ADPF-54 e na liminar:

Eis porque não se revela correta a afirmação do il. advogado da autora quando, a buscar fazer prevalecer o direito da gestante, registrou que “... por fatalidade, não há viabilidade de uma outra vida, sequer um nascituro, cujo interesse se possa eficazmente proteger".

O bebê anencéfalo, por certo nascerá.

Pode viver segundos, minutos, horas, dias, e até meses. Isto é inquestionável! (Fonteles, 2004, p. 09)

A retórica de argumento ainda foi utilizada para defender a sentença do direito à vida do embrião, desde o momento da concepção:

Se o tratamento normativo do tema, como vimos (itens 34/37, deste parecer), marcadamente protege a vida, desde a concepção, por certo é inferência lógica, inafastável, que o direito à vida não se pode medir pelo tempo, seja ele qual for, de uma sobrevida visível. (Fonteles, 2004, p. 09)

Combinada com o direito categorial, a retórica de argumento também foi usada para isentar o Procurador da possível acusação de confundir valores religiosos com questões laicas: "Estabeleço, portanto, e em construção estritamente jurídica, que o direito à vida é a temporal, vale dizer, não se avalia pelo tempo de duração da existência humana" (Fonteles, 2004, p. 09).

Para a defesa da supremacia do valor da vida do feto, em detrimento do valor da vida da gestante, Fonteles minimizou as possíveis frustrações que a gestante poderia sofrer. A organização retórica dos argumentos foi de sobreposição da crença do amor maternal, invocando a mártir que supostamente haveria em cada mulher por ter, como desígnio, ser mãe. Essa organização retórica foi combinada com a defesa da afirmação de que o Estado tem o dever de proteger a vida do embrião, impondo à mulher a obrigação de gestar um feto inviável:

É de se reconhecer, outrossim, e mantido o raciocínio na ponderação de bens, que por certo o sofrer uma dor, mesmo que intensa, não ultrapassa o por cobro a uma vida, que existe, intrauterina, e que, seja sempre reiterado, goza de toda a proteção normativa, tanto sob a ótica do direito interno, quanto internacional. (Fonteles, 2004, pp. 09-10)

Finalmente, o apelo emocional a uma sociedade fraterna foi o recurso usado pelo Procurador para opor a defesa da vida da gestante à defesa da vida do feto, empregando metáforas de efeito vinculador entre os sentidos de vida e de morte.

O pleito da autora, por certo, vai na contra-mão da construção da sociedade solidária a que tantos de nós, brasileiras e brasileiros, aspiramos, e o ser solidário é modo eficaz de instituir a cultura da vida. (Fonteles, 2004, p. 10) 
A formulação de listas e contrastes foi usada por Fonteles para opor-se ao argumento da CNTS e do Ministro Marco Aurélio de que o feto anencefálico não tem cérebro. A estratégia foi enumerar os outros órgãos que se formam no feto e redirecionar a ênfase da não-formação do cérebro, dada pelas argumentações opostas ao do procurador-geral:

E nos casos de anencefalia há o normal desenvolvimento físico do feto: formam-se seus olhos; nariz; ouvidos; boca; mãos, enfim o que lhe permite sentir, e também braços; pernas; pés; pulmões; veias; sangue que corre, o coração. (Fonteles, 2004, p. 08)

Esta estratégia retórica buscou nomear as características humanas do feto por meio da enumeração do desenvolvimento de aspectos físicos característicos da espécie humana, numa organização retórica que visou enfatizar a valorização da vida como valor intrínseco, ou seja, a vida do feto seria sagrada e intocável pelo fato de pertencer à espécie humana.

\section{Considerações finais}

A análise interpretativa da liminar do Ministro Marco Aurélio mostrou que seu arranjo retórico visou enunciar a frustração da vida do feto com consequente risco para a vida da gestante. A retórica forense combinou-se com a deliberativa para atestar a versão factual defendida pelo relator da liminar, que enumerou os direitos da gestante a serem defendidos, em oposição implícita ao suposto direito à vida do feto.

No parecer do procurador-geral da República, Claudio Fonteles, a defesa do direto do feto à vida foi considerada uma primazia jurídica desde a concepção. Para Fonteles, os casos em que é permissível abortar - para salvar a vida da gestante e nos casos em que a permissibilidade baseia-se no fato de a gestante ter sido vítima de estupro, qualificando moralmente o ato - seriam as exceções que justificariam a valorização da vida da gestante em detrimento da vida do feto. Ou seja, seria permissível abortar nesses casos porque, além de estar previsto no Código Penal, haveria ameaça ao sentimento materno como "dom" divino concedido a todas as mulheres, o que poderia prejudicar a vida do feto: no caso do risco de vida da gestante, porque o fim da vida dela ocasionaria o fim da vida do feto, e, no caso do estupro, porque o sentimento de maternidade, possivelmente abalado pelo trauma da violência sexual, prejudicaria o investimento afetivo da gestante na vida do feto.

A criminalização do aborto nos casos de anencefalia impede que as mulheres façam uma escolha, sendo constrangidas, pela lei, a continuar a gravidez. No momento em que religiosos assumem posições governamentais e pressionam o Estado no sentido da criminalização do aborto, como o fez o Claudio Fonteles, eles estão impedindo que, no plano religioso, os indivíduos façam escolhas morais. Se a legislação e sua interpretação forem determinadas por diretrizes religiosas, estamos de fato impedindo a liberdade de credo e utilizando o poder do Estado para garantir que todos os cidadãos sigam tais diretrizes. Os católicos têm direito de defender suas ideias, mas não de impô-las a todos por meio dos aparelhos de Estado. Portanto, um cristão, no exercício de funções no Estado de direito, deveria atuar em defesa da pluralidade moral e da liberdade de crenças, e não impor suas próprias crenças, obrigando uma mulher a carregar um feto que morrerá. 


\section{Colaboradores}

As autoras participaram igualmente da elaboração do manuscrito.

\section{Referências}

BILLIG, M. Ideology and opinions: studies in rhetorical psychology. London: Sage, 1991.

DINIZ, D.; VELEZ, A.C.G. Aborto na Suprema Corte: o caso da anencefalia no Brasil. Rev. Estud. Fem., v.16, n.2, p.647-52, 2008.

DOMINGUES, R.C. Entre normas e fatos, o direto de decidir: o debate sobre o aborto à luz dos princípios constitucionais. In: MAIA, M.B. (Org.). Direito de decidir: múltiplos olhares sobre o aborto. Belo Horizonte: Autêntica, 2008.

DWORKIN, R. O Domínio da vida: aborto, eutanásia e liberdades individuais. Trad. Jefferson Luiz Camargo. São Paulo: Martins Fontes, 2003. p. - .

FONTELES, C. Parecer n. ${ }^{\circ}$ 3358/CF. Supremo Tribunal Federal. Disponível em: www.stf. jus.br. Acesso: maio 2007.

LEACH, J. Análise retórica. In: BAUER, M.W.; GASKELL, G. (Eds.). Pesquisa qualitativa com texto, imagem e som: um manual prático. Trad. Pedrinho Arcides Guareschi. Petrópolis: Vozes, 2002. p. 293-318.

MELLO, M.A. Med. caut. em arguição de descumprimento de preceito fundamental 54-8 distrito federal. Supremo Tribunal Federal. Disponível em: www.stf.jus.br. Acesso: maio 2007

ORGANIZAÇÃO MUNDIAL DE SAÚDE - OMS. Abortamento seguro: orientação técnica e de políticas para os sistemas de saúde. Campinas: Cemicamp, 2004.

POTTER, J. La representación social de la realidad: discurso, retórica y construcción social. Barcelona: Paidós, 1996.

REDE FEMINISTA DE SAÚDE. Dossiê Aborto: mortes preveníveis e evitáveis - dossiê. Belo Horizonte: Rede Feminista de Saúde, 2005.

RIBEIRO, F. R. G. Sentidos da vida na controvérsia moral sobre o abortamento induzido: o caso da anencefalia. Dissertação (Mestrado em Psicologia Social). Pontifícia Universidade Católica de São Paulo: São Paulo, 2008. 
RIBEIRO, F.R.G.; SPINK, M.J. Estrategias retóricas de la controversia moral sobre la legalización del aborto: el caso de anencefalia en Brasil. Interface - Comunic., Saude, Educ., v.16, n.40, p.35-49, jan./mar. 2012.

Se discute la construcción de las estrategias retóricas en la controversia sobre el aborto en Brasil. El análisis se centra en dos documentos: la deliberación liminar del Ministro Marco Aurélio que en 2004 autorizó la interrupción de la gestación de anencefálicos y el parecer del Procurador-General de la República que se manifestó contrario a esta decisión. La metodología consistió en la interpretación de los recursos estratégicos de la argumentación favorable y contraria a la legalización del aborto. Los argumentos favorables se sustentan en la retórica de la evaluación de la vida de la gestante que pudiera tener más intereses a proteger que el feto, por ser invertida biográficamente, mientras la inversión en la vida del feto sería sólo de carácter biológico. Los argumentos contrarios construyen una retórica de defensa de la vida del feto porque pertenece a la especie humana. El análisis indica que la sobreposición de valores religiosos en la valuación de los derechos reproductivos obstaculiza la efectividad de la asistencia a la salud de la mujer.

Palabras clave: Retórica. Anencefalia. Aborto. Salud de la mujer. 
